Proceeding Paper

\title{
Comparing Accuracy of Three Remote Sensing Methods to Evaluate Soil Impact Related to Forest Operations ${ }^{\dagger}$
}

\author{
Francesco Latterini 1,*, Rachele Venanzi ${ }^{2}$, Damiano Tocci ${ }^{2}$, Federico Moschetti ${ }^{2}$ and Rodolfo Picchio ${ }^{2}$ \\ 1 Consiglio per la Ricerca in Agricoltura e l'Analisi dell'Economia Agraria, Centro di Ricerca in Ingegneria e \\ Trasformazioni Agroalimentari, Via della Pascolare 16, 00015 Monterotondo, Italy \\ 2 Department of Agricultural and Forest Sciences, University of Tuscia, 01100 Viterbo, Italy; \\ venanzi@unitus.it (R.V.); toccidamiano91@gmail.com (D.T.); federicomoschetti@hotmail.it (F.M.); \\ r.picchio@unitus.it (R.P.) \\ * Correspondence: francesco.latterini@crea.gov.it
}

Citation: Latterini, F.; Venanzi, R.; Tocci, D.; Moschetti, F.; Picchio, R. Comparing Accuracy of Three Remote Sensing Methods to Evaluate Soil Impact Related to Forest Operations. Environ. Sci. Proc. 2021, 3, 59. https://doi.org/10.3390/ IECF2020-07954

Academic Editors: Angela Lo Monaco, Cate Macinnis-Ng and Om P. Rajora

Published: 12 November 2020

Publisher's Note: MDPI stays neutral with regard to jurisdictional claims in published maps and institutional affiliations.

\section{(c) (i)}

Copyright: $\odot 2020$ by the authors. Licensee MDPI, Basel, Switzerland. This article is an open access article distributed under the terms and conditions of the Creative Commons Attribution (CC BY) license 
(http://creativecommons.org/licenses /by/4.0/).
† Presented at the 1st International Electronic Conference on Forests-Forests for a Better Future: Sustainability, Innovation, Interdisciplinarity, 15-30 November 2020; Available online: https://iecf2020.sciforum.net.

\begin{abstract}
Monitoring soil impacts related to forest operations is crucial to reach the sustainable forest management goal. On the other hand, field survey to assess such kind of impact is usually costly and time consuming. Therefore, the possibility of using remote and proximal sensing technologies to analyze forest soil impacts could be very helpful for forest managers. According to this, the aim of the present work was the evaluation of reliability of three different remote sensing tools for the assessment of soil impacts related to forest operations. The study area consisted in an oak coppice located in the Municipality of Castel Giorgio (Terni District, Central Italy). The different tested technologies were Sentinel-2, Google Earth and an unmanned aerial vehicle equipped with an RGB sensor. After forest utilization, images of the study area were obtained by the abovementioned systems, and a photo-interpretation process allowed the identification of skid trails patterns produced by the operators during the extraction of timber. The three theoretical skid trails patterns were compared with the real one, obtained by field relief with Global Navigation Satellite Systems (GNSS) technology. The obtained results showed that all these systems still need some improvements for an effective application in the Italian forest sector, concerning soil impacts evaluation after forest operations.
\end{abstract}

Keywords: Google Earth; unmanned aerial vehicle; GNSS; GIS; Central Italy

\section{Introduction}

One of the main goals of sustainable forest management is making sure that forest utilization meets the requirements of all three pillars of sustainability [1]. A key issue to achieve this goal is carrying out forest operations with the aim to minimize the negative impact of harvesting, without limiting work productivity as well as assuring safety of forest workers [2-4]. Focusing in particular on soil impact related to forest utilization, a major factor in damaging soil is machinery traffic, which is able to cause compaction, soil mixing and topsoil removal [5-8].

Ground reduction and damage to regeneration caused by silvicultural treatments and forest operations remain therefore a key topic [9].

As above-mentioned, monitoring soil impacts related to forest operations is crucial. The current monitoring process of impacts to soil is mainly performed through soil samples collection and analysis, or measured using specific instruments, such as penetrometer and scissometer [10]. These methods are however time consuming and costly [11].

A possible solution to this issue concerns the application of remote and proximal sensing techniques in order to assess the spatial distribution of soil impacts [11,12]. In this regard, scientific research has been putting effort into assessing the efficiency of various technologies for the evaluation of soil microtopography changes, in relation to forest machinery traffic. In particular, terrestrial laser scanning (TLS) gave good results [13,14], while airborne laser scanning (ALS) showed a good performance in similar tests, not performed on forest environment [15], as well as in the identification of soil moisture in order to avoid forest utilization to be carried out in difficult conditions [12]. On the other hand, the effectiveness of remote sensing techniques for the evaluation of soil impacts has not been widely studied yet.

The goal of the present work was to properly evaluate the effectiveness of some remote sensing and proximal sensing techniques for the assessment of soil impacts related to forest operations, with particular focus on the amount of surface area impacted by machineries during extraction operations. Three different approaches have been considered to detect the tracks of machinery passes: Google Earth images, Sentinel-2 images and high-definition images provided by an unmanned aerial vehicle (UAV) 
equipped with RGB sensor. A GNSS field relief was considered as a control in order to make a comparison with the obtained results.

\section{Materials and Methods}

\subsection{Study Area}

The study area was located in Castel Giorgio municipality (Umbria, Italy). Selected stand was coppice forest of two species: turkey oak (Quercus cerris L.) and chestnut (Castanea sativa Mill.) with a surface area of about 16 ha. The average height is $580 \mathrm{~m}$ a.s.l. with a prevalent slope of $10 \%$ and a maximum slope of 35\% (Figure 1). Coppicing interventions, with the release of 80 standards per hectare, were performed in 2017-2018. The harvesting system consisted of the tree length system (TLS), with motor-manual felling by chainsaw and extraction by wheeled grapple skidder.

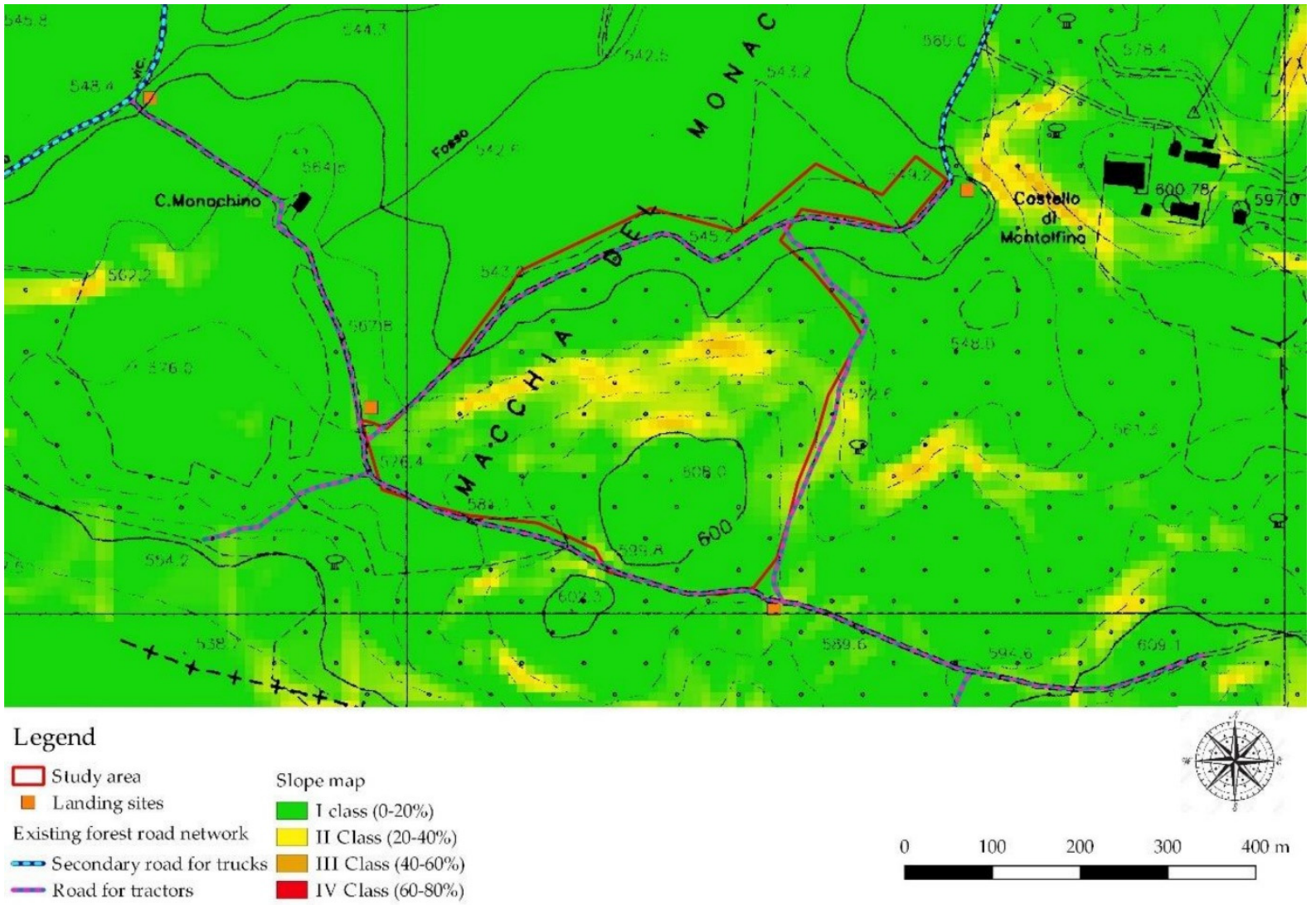

Figure 1. Study area, existing forest road network and landing sites overlaid on the slope map.

\subsection{Field Relieves}

After the end of the forest utilization, a GNSS relief with a Trimble Juno handheld receiver [16] was used for the identification and recording of the all skid trails opened during the extraction operation; the width of each skid trail has been recorded through measuring it with a measure tape.

After four months, the relief with an UAV took place. The limited duration of the battery made the survey of just four ha possible. In this area, the relief with RGB sensors allowed to obtain high-resolution raster images $(50 \mathrm{~cm}$ pixel).

\subsection{Detection of Impacted Surface}

The tracks recorded through the GNSS receiver were imported in Quantum GIS 2.18 software [17] in order to be converted into shapefile format for further analysis. 
Google Earth images of the area were imported into QGIS software interface through the plugin "Quick Map Service" and, by a photo-interpretation process, a line shapefile bearing the "new" skid trails detectable through satellite images (i.e., skid trails not previously present and reported in Figure 1) was created. UAV.

A similar procedure was applied for the high-resolution images provided by the

Concerning the Sentinel-2 satellite images, they were firstly downloaded from the dedicated website [18] and imported in QGIS, then a real-color image of the area was created to perform the photo-interpretation process, as applied for the other investigated systems.

It is important to underline that for Google earth and Sentinel-2 images it was possible to investigate all the study area, while for the UAV the analysis was limited to only 4 ha.

After processing the shapefiles of the various theoretical skid trails network, twenty virtual sample plots with round shape of $1256 \mathrm{~m}^{2}$ each (radius $20 \mathrm{~m}$ ) were randomly identified within the intervention surface, to make possible the comparison between the real skid trails network (obtained by GNSS relief) and the theoretical network obtained by Google earth and Sentinel-2 images. A similar procedure was applied for the UAV skid trails network, but the dimension of the virtual sample plots was reduced to $314 \mathrm{~m}^{2}$ each (radius of $10 \mathrm{~m}$ ). Within each virtual sample plot, the skid trails length was identified in order to estimate the forest road density $\left(\mathrm{m} \mathrm{ha}^{-1}\right)$ and the impacted surface $(\%)$, this last considering the average width of skid trails detected in the previous field relief.

A dependent samples $t$-test was performed to detect the presence of statistically significant differences between the control skid trails, obtained through GNSS, and the skid trails obtained through the different investigated approaches.

\section{Results}

The first result of the work concerns the remark about the uselessness of Sentinel-2 images for impacted surface detection during forest operations. Indeed, the $10 \mathrm{~m}$ pixel of Sentinel-2 images does not allow the skid trail identification on the pattern, as reported in Figure 2.

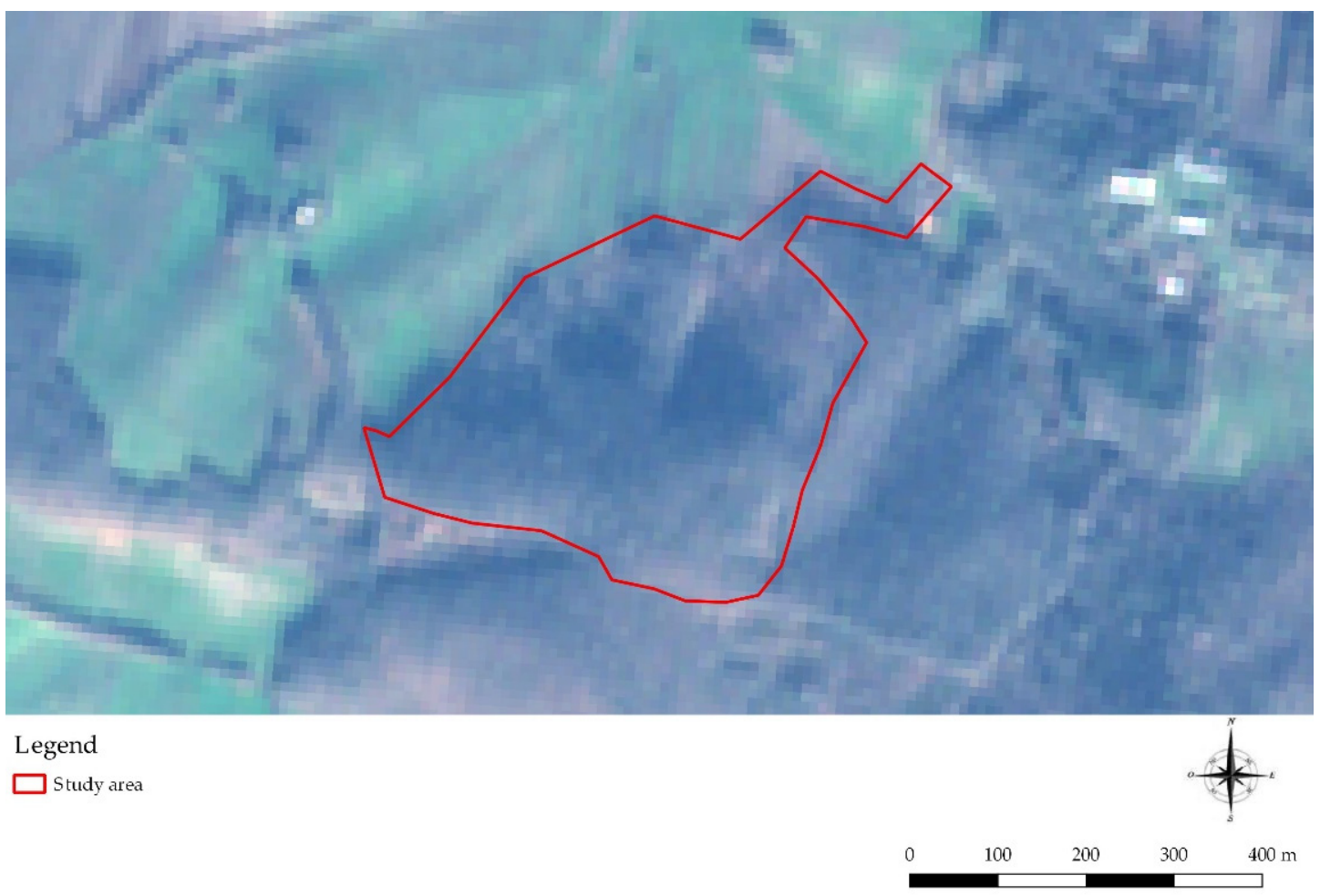


Figure 2. Study area overlapped on a real color image obtained by Sentinel-2. As it is possible to notice, the $10 \mathrm{~m}$ pixel dimension does not allow the identification of the skid trails pattern.

The comparison between the Google Earth skid trails pattern (GE) and the control pattern (GNSS) showed that there was a bigger average impacted surface detected and bigger road density when using GNSS (Table 1, Figure 3).

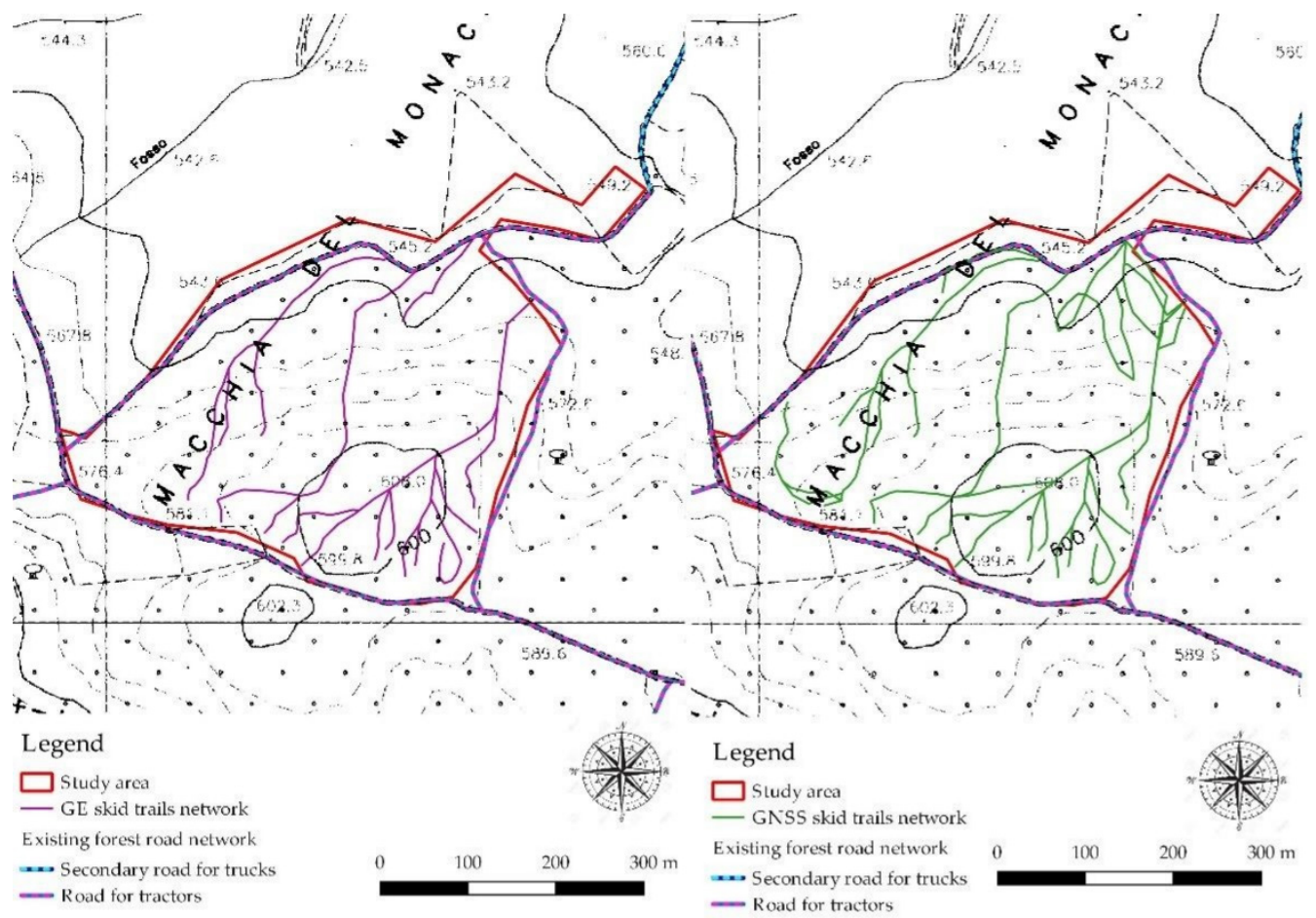

Figure 3. Comparison between skid trails patterns identified with Google Earth (GE) (on the left) and Global Navigation Satellite Systems (GNSS) (on the right).

Table 1. Results of the $t$-test for the comparison between the skid trail pattern detected through Google Earth images (GE) and the control one (GNSS).

\begin{tabular}{ccccc}
\hline & \multicolumn{2}{c}{ GE } & \multicolumn{2}{c}{ GNSS } \\
\hline & Avg. & St.Dev & Avg. & St.Dev. \\
Impacted surface $(\%)^{*}$ & 7.96 & 6.41 & 10.58 & 7.56 \\
Road density $\left(\mathrm{m} \mathrm{ha}^{-1}\right)^{*}$ & 227 & 183 & 302 & 216 \\
\hline
\end{tabular}

* Represents a statistically significant difference at $p>0.05$ according to dependent samples $t$-test.

As it is possible to notice, there is a significant underestimation of both the impacted surface and forest road density, according to the results of the dependent samples $t$-test.

The comparison between the skid trails pattern obtained through RGB sensors and unmanned aerial vehicle (UAV) showed that there was bigger average impacted surface detected and bigger road density when using UAV (Table 2, Figure 4). 


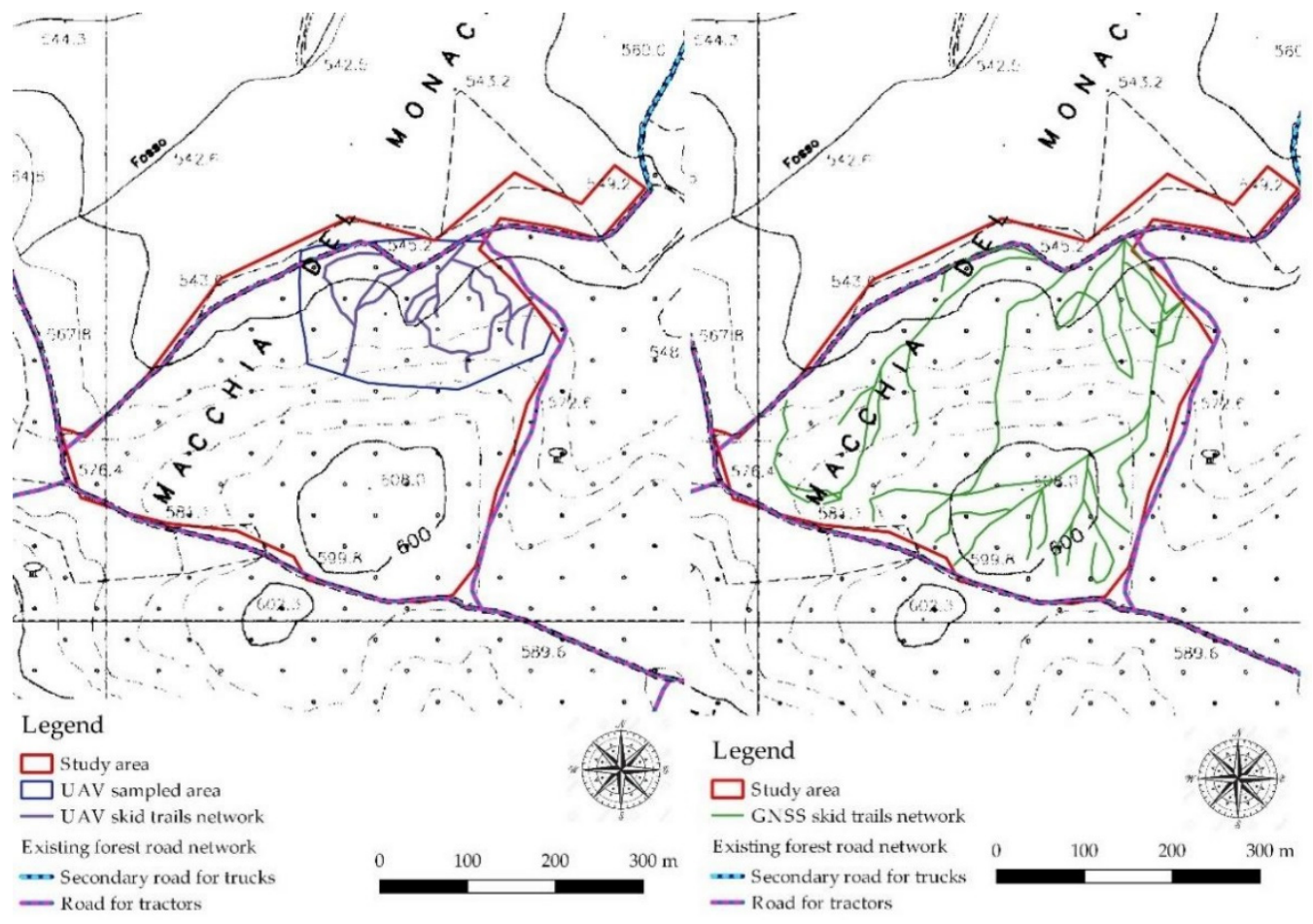

Figure 4. Comparison between the skid trails pattern identified with GE (on the left) and GNSS pattern (on the right).

Table 2. Results of the $t$-test for the comparison between the skid trails pattern detected through Google Earth images (GE) and the control one (GNSS).

\begin{tabular}{ccccc}
\hline & \multicolumn{2}{c}{ UAV } & \multicolumn{2}{c}{ GNSS } \\
\hline & Avg. & St.Dev & Avg. & St.Dev. \\
Impacted surface $(\%)^{*}$ & 14.04 & 12.34 & 10.58 & 7.56 \\
Road density $\left(\mathrm{m} \mathrm{ha}^{-1}\right)^{*}$ & 401 & 353 & 302 & 216 \\
\hline
\end{tabular}

${ }^{*}$ Represents a statistically significant difference at $p>0.05$ according to dependent samples $t$-test.

In contrast to what was reported for GE, UAV showed a significant overestimation of both the impacted surface and forest road density, in comparison with the control skid trail pattern. 


\section{Discussions and Conclusions}

The first evidence, which was predictable, is that Sentinel-2 images, which are the highest resolution images freely available with short time lag (few days), are not suitable for the detection of forest soil impact related to machinery passing. The $10 \mathrm{~m}$ pixel is indeed not accurate enough to detect the tracks. So, even if Sentinel-2 is a very powerful tool for several forest application, it is not effective in soil impact monitoring.

As a consequence, to deal with remote sensing in forest utilization, higher definition images are needed, which are generally not free to use.

A partial exception consists in Google earth images, which are freely available, even if the updating time is about 1-2 years, which is obviously a substantial limit to carry out the monitoring of forest soil impacts.

It is therefore needed to have Google Earth images close in time to the utilization, and this is not always possible.

On the other hand, even if the statistical analysis revealed a significant underestimation of the impacted surface in comparison with the control skid trails pattern, Google Earth images seem to be a useful instrument. Moreover, it is important to underline that in this case, a high mechanization level was implemented, consequently making the skid trails identification easier because of the substantial dimensions of the machineries used. According to this, it could be interesting to evaluate the performance of Google Earth images also in small scale mechanization forest yards.

Concerning the UAV with the RGB sensor, it certainly was revealed to be an interesting instrument, even if with some limitations. The obtained results showed an overestimation of the impacted surface, so a few actually non-existing skid trails were identified as machinery tracks.

To avoid this, it is important to improve the know-how of the operator within the process of photointerpretation, as well as investigating the performance of different sensors, for example LiDAR. Moreover, the main limit consisted in the limited battery life which, currently, does not allow the relief of areas in accordance with the typical dimension of forest yards in Central Italy.

\section{To summarize:}

- Currently, the best remote sensing system to monitor soil impacts related to forest utilization consists of high-resolution satellite images, which however are not freely available according to the needed short time lag, and considering that Google Earth does not ensure enough short time lag.

- $\quad \mathrm{UAV}$ is a very interesting technology, which however needs to be further improved to be efficient in the conditions of Central Italy forestry.

- GNSS field relief, even if costly and time consuming, is currently the best solution to monitor soil impacts related to forest operations, as reported also by Ellis et al., 2016 [19].

Author Contributions: Conceptualization, F.L. and R.P.; methodology, F.L., R.V., D.T., F.M. and R.P.; validation, F.L. and R.P.; data curation, F.L., D.T., F.M., and R.P.; writing-original draft preparation F.L., R.V., D.T., F.M., and F.L.; writing - review and editing, F.L., R.V., D.T., F.M. and R.P.; supervision, R.P. All authors have read and agreed to the published version of the manuscript

Funding: the research received no external funding.

Conflicts of Interest: The authors declare no conflict of interest.

\section{References}

1. Schweier, J.; Blagojević, B.; Venanzi, R.; Latterini, F.; Picchio, R. Sustainability assessment of alternative strip clear cutting operations for wood chip production in renaturalization management of pine stands. Energies 2019, 12, 3306, doi:10.3390/en12173306.

2. Marchi, E.; Chung, W.; Visser, R.; Abbas, D.; Nordfjell, T.; Mederski, P.S.; McEwan, A.; Brink, M.; Laschi, A. Sustainable Forest Operations (SFO): A new paradigm in a changing world and climate. Sci. Total Environ. 2018, 634, 1385-1397.

3. Picchio, R.; Magagnotti, N.; Sirna, A.; Spinelli, R. Improved winching technique to reduce logging damage. Ecol. Eng. 2012, 47, 83-86. 
4. Picchio, R.; Latterini, F.; Mederski, P.S.; Tocci, D.; Venanzi, R.; Stefanoni, W.; Pari, L. Applications of GIS-based software to improve the sustainability of a forwarding operation in Central Italy. Sustainability 2020, 12, 5716, doi:10.3390/su12145716.

5. Korb, J.E.; Fulé, P.Z.; Gideon, B. Different restoration thinning treatments affect level of soil disturbance in ponderosa pine forests of northern Arizona, USA. Ecol. Restor. 2007, 25, 43-49.

6. Klvač, R.; Vrána, P.; Jiroušek, R. Possibilities of using the portable falling weight deflectometer to measure the bearing capacity and compaction of forest soils. J. For. Sci. 2010, 56, 130-136.

7. Williamson, J.R.; Neilsen, W.A. The influence of forest site on rate and extent of soil compaction and profile disturbance of skid trails during ground-based harvesting. Can. J. For. Res. 2000, 30, 1196-1205.

8. Grigal, D.F. Effects of extensive forest management on soil productivity. For. Ecol. Manag. 2000, 138, 167-185.

9. Venanzi, R.; Picchio, R.; Grigolato, S.; Latterini, F. Soil and forest regeneration after different extraction methods in coppice forests. For. Ecol. Manag. 2019, 454, 117666, doi:10.1016/j.foreco.2019.117666.

10. Venanzi, R.; Picchio, R.; Piovesan, G. Silvicultural and logging impact on soil characteristics in Chestnut (Castanea sativa Mill.) Mediterranean coppice. Ecol. Eng. 2016, 92, 82-89.

11. Cambi, M.; Giannetti, F.; Bottalico, F.; Travaglini, D.; Nordfjell, T.; Chirici, G.; Marchi, E. Estimating machine impact on strip roads via close-range photogrammetry and soil parameters: A case study in Central Italy. IForest 2018, 11, 148-154, doi:10.3832/ifor2590-010.

12. Talbot, B.; Pierzchała, M.; Astrup, R. Applications of remote and proximal sensing for improved precision in forest operations. Croat. J. For. Eng. 2017, 38, 327-336, doi:10.5281/zenodo.890539.

13. Koren, M.; Slančík, M.; Suchomel, J.; Dubina, J. Use of terrestrial laser scanning to evaluate the spatial distribution of soil disturbance by skidding operations. IForest 2015, 8, 386.

14. Giannetti, F.; Chirici, G.; Travaglini, D.; Bottalico, F.; Marchi, E.; Cambi, M. Assessment of soil disturbance caused by forest operations by means of portable laser scanner and soil physical parameters. Soil Sci. Soc. Am. J. 2017, 81, 1577-1585.

15. Roosevelt, C.H. Mapping site-level microtopography with real-time kinematic global navigation satellite systems (RTK GNSS) and unmanned aerial vehicle photogrammetry (UAVP). Open Archaeol. 2014, 1, doi:10.2478/opar-2014-0003.

16. Trimble Juno. Available online: https://geospatial.trimble.com/products-and-solutions/juno-5 (accessed on 10 June 2020 ).

17. QGIS Geographic Information System. Open Source Geospatial Foundation Project. Available online: http://qgis.org QGIS official site (accessed on 6 June 2020).

18. Sentinel Hub. Available online: https://www.sentinel-hub.com/ (accessed on 10 June 2020).

19. Ellis, P.; Griscom, B.; Walker, W.; Gonçalves, F.; Cormier, T. Mapping selective logging impacts in Borneo with GPS and airborne lidar. For. Ecol. Manag. 2016, 365, 184-196, doi:10.1016/j.foreco.2016.01.020. 